\title{
Caracterização de frutos de genótipos de muricizeiros cultivados no litoral cearense ${ }^{1}$
}

\author{
Characterization of fruits from genotypes of the nance tree grown along the coast of \\ Ceará
}

\author{
Isabel Peixoto Lourenço ${ }^{2 *}$, Raimundo Wilane de Figueiredo ${ }^{3}$, Ricardo Elesbão Alves ${ }^{4}$, Fernando Antonio Souza \\ de Aragão $0^{4}$ e Carlos Farley Herbster Moura ${ }^{4}$
}

\begin{abstract}
RESUMO - Das espécies frutíferas nativas do Nordeste, o muricizeiro (Byrsonima dealbata Griseb) destaca-se dupla finalidade, consumo "in natura" e industrialização. As populações locais vivem do extrativismo e tem no murici uma fonte de renda, comercializando-o em feiras livres. Apesar da importância social das espécies frutíferas nativas para algumas regiões, no entanto, há poucas informações a cerca destas espécies. Em vista do exposto, o objetivo foi avaliar frutos de diferentes genótipos de muricizeiros por meio da caracterização biométrica e as relações genéticas entre os mesmos. Analisaram-se 18 genótipos de muricizeiros, oriundos dos municípios Pacajus, Fortaleza e Paraipaba, CE. Foram realizadas 30 medições, onde cada medição correspondeu a um fruto, nos quais foram analisados: massa, diâmetro, comprimento, cor $\left(\mathrm{L}, \mathrm{a}^{*}, \mathrm{~b}^{*}\right)$, firmeza e rendimento, sendo este com base em $100 \mathrm{~g}$ de polpa. Dos resultados obtidos obteve-se predominância de frutos oblongos, com destaque para o genótipo EM 4 por apresentar maior massa dos frutos. Foram estimadas: variância residual, variância genética, repetibilidade e correlações fenotípicas entre as variáveis estudadas. As técnicas multivariadas aplicadas (agrupamento de genótipos por meio da otimização de Tocher, análise de componentes principais e análise da dissimilaridade dos genótipos, expressa em dendrograma, com base no método do vizinho mais próximo) foram concordantes entre si, demonstrando que os genótipos EM 3, EM 4 e PAC 6 foram divergentes entre si e entre os demais, possuindo variabilidade genética, permitindo potencial uso dos mesmos em programas de melhoramento.
\end{abstract}

Palavras-chave: Byrsonima dealbata. Murici. Frutas tropicais. Dispersão gráfica.

\begin{abstract}
Of the species of fruits native to the northeast of Brazil, the nance tree (Byrsonima dealbata Griseb) stands out for offering the potential for both fresh consumption and industrialization. The local populations live by harvesting fruits, and find a source of income in the nance fruit, selling it in street markets. Despite the social importance of those fruit species which are native to certain regions, there is little information about these species. In view of the above, the objective here was to evaluate the fruits of different nance genotypes, using biometric characterization and the genetic relationships between those genotypes. Eighteen genotypes of the nance were analysed, taken from the municipalities of Pacajus, Fortaleza and Paraipaba in the state of Ceará. Thirty measurements were taken, each corresponding to a single fruit, in which the following were analysed: weight, diameter, length, color (L, $\left.a^{*}, b^{*}\right)$ firmness and yield, this last being based on $100 \mathrm{~g}$ of pulp. From the results, oblong fruit were predominant, especially the EM 4 genotype which presented the greatest weight. The residual variance, genetic variance, repeatability and phenotypic correlations between variables were all estimated. The multivariate techniques used (genotype clustering using Tocher optimisation, principal-component analysis, and analysis of the dissimilarity of the genotypes expressed as a dendrogram based on nearest-neighbor methodology) had similar results, showing that the three genotypes EM 3, EM 4 and PAC 6 presented different results from each other and the rest of the group, having a genetic variability which would potentially allow for usage in breeding programs.
\end{abstract}

Key words: Byrsonima dealbata. Nance. Tropical fruits. Graphic dispersion.

\footnotetext{
*Autor para correspondência

'Recebido para publicação em 25/10/2011; aprovado em 03/10/2012

Parte de Dissertação de Mestrado da primeira autora, apresentado ao Programa de Pós-Graduação em Agronomia/Fitotecnia, CCA/UFC

2Departamento de Fitotecnia, Centro de Ciência Agrária/UFC, Fortaleza-CE, isabelpxl@ hotmail.com

${ }^{3}$ Departamento de Tecnologia de Alimentos, Centro de Ciência Agrária, Universidade Federal do Ceará, Campus do Pici, Bloco 858, Fortaleza-CE, Brasil, 60.356-000, figueira@ufc.br

${ }^{4}$ Emprapa Agroindústria Tropical, Fortaleza-CE, Brasil, ricardo.alves@embrapa.br, elesbao@pesquisador.cnpq.br, farley@cnpat.embrapa.br
} 


\section{INTRODUÇÃO}

$\mathrm{O}$ patrimônio natural brasileiro expresso em sua extensão continental, diversidade de espécies biológicas e patrimônio genético, bem como pela variedade de biomas, apresenta grande relevância mundial (ASSUNÇÃO; FELFILI, 2004).

Das espécies frutíferas nativas do Nordeste brasileiro destaca-se o muricizeiro (Byrsonima dealbata Griseb), por apresentar potencial tanto para o consumo in natura, (DONADIO; MÔRO; SERVIDONE, 2002) quanto para processamento industrial para fabricação de polpa, suco, licor, geléias e sorvetes (ALVES; FRANCO, 2003), o odor característico do fruto maduro é semelhante ao de queijo rançoso (REZENDE; FRAGA, 2003). As populações locais que vivem do extrativismo têm o murici como uma importante fonte de renda, sendo comum sua comercialização em feiras livres (GUSMÃO; VIEIRA; FONSECA JÚNIOR, 2006). As informações sobre este fruto são escassas (PEREIRA, 2001), portanto, o desenvolvimento de pesquisas que visem à geração de conhecimentos e tecnologias que permitam melhores formas de aproveitamento desta espécie poderá contribuir para inseri-la no agronegócio regional e nacional.

A biometria dos frutos constitui um instrumento importante para detectar a variabilidade genética dentro de populações de uma mesma espécie, tal como a repetibilidade, que pode ser enunciada como sendo a correlação entre as medidas de determinado caráter em um mesmo indivíduo, cujas avaliações foram repetidas no tempo ou espaço(CRUZ; REGAZZI, 1994), e tem sido utilizada com certa frequência em diversas espécies semiperenes e perenes, como o capim-elefante (SHIMOYA et al., 2002), cana de açúcar (FERREIRA et al., 2005; SANTOS et al., 2004), cajazeira (SOARES et al., 2008), laranjeira-doce (NEGREIROS et al., 2008), dentre outras, bem como as relações entre a variabilidade e os fatores ambientais, importantes para os programas de melhoramento genético.

Para determinar as relações genéticas de uma população ou genótipo em relação à outra população ou genótipo da mesma espécie, são utilizados métodos biométricos analisados pela estatística multivariada, permitindo unificar múltiplas informações de um conjunto de caracteres. Vários métodos podem ser utilizados, entre eles, análise por componentes principais, variáveis canônicas e métodos aglomerativos. A escolha do método depende da precisão desejada pelo pesquisador, da facilidade da análise e de como os dados foram obtidos (CRUZ; REGAZZI; CARNEIRO, 1994). $\mathrm{O}$ uso da análise multivariada em divergência genética tem sido assunto de extensas pesquisas em várias culturas, como a cana de açúcar (DUTRA FILHO et al., 2011), Capsicum (TOQUICA et al., 2003; ZEWDIE;
TONG; BOSLAND, 2004), feijão-vagem (PEIXOTO et al., 2002), entre outros.

Costa, Oliveira e Moura (2001) descrevem em trabalho com açaizeiro, que um dos maiores problemas dos recursos genéticos é a escassez de informações sobre a caracterização genética, devido carência de estudos sobre diversidade genética de espécies com potencial econômico para região norte, principalmente as frutas nativas do Brasil. Portanto, objetivou-se caracterizar biometricamente frutos de diferentes genótipos de muricizeiro cultivados no litoral cearense e as relações genéticas entre os mesmos.

\section{MATERIAL E MÉTODOS}

Foram selecionados muricizeiros oriundos do município de Pacajus (PAC 0, PAC 1, PAC 2, PAC 3, PAC 5, PAC 6, PAC 7), do município de Fortaleza (EM 1, EM 3 , EM 4, EM 5) e do município de Paraipaba (PAR 3, PAR 4, PAR 5, PAR 7, PAR 9, PAR 11 e PAR 12), totalizando 18 genótipos. Os frutos foram colhidos maduros, por genótipo, etiquetados, acondicionados em isopor e transportados para o laboratório. Foram realizadas 30 medições de fruto por genótipo, correspondendo a 30 frutos avaliados individualmente, exceto para rendimento de polpa onde realizou três medições a partir do peso de $100 \mathrm{~g}$ de polpa de frutos, expresso em $\%\{100$ - [(peso do caroço $x$ 100)/ peso total] \}, As demais variáveis estudadas foram: massa do fruto (g) através de balança analítica, diâmetros equatorial e comprimento $(\mathrm{mm})$ a partir da porção compreendida entre a região basal e a apical, com auxílio de paquímetro digital, coloração externa dos frutos pelo uso do colorímetro, modelo CR-300 (parâmetros L, a*, b*) e firmeza da polpa medida em texturômetro modelo TA-XT2i, Stable Micro Systems, ponteira de $2 \mathrm{~mm}$ expressos em $\mathrm{N}$.

A disposição geográfica das plantas e coleta dos frutos não se adéquam a um modelo experimental que permite o uso da Análise de Variância, todavia, foram adotadas análises estatísticas uni e multivariadas apropriadas aos dados do referido estudo. Por meio de análises univariadas foram estimadas: variância residual (dentre genótipos) e variância genética (entre genótipos), coeficiente de repetibilidade, coeficiente de determinação, número de medições necessárias para obtenção dos níveis de certeza de 95 e $99 \%$ e correlações fenotípicas. Como o agrupamento em dendrograma é subjetivo recomenda-se a utilização de mais de um método de agrupamento para escolha do resultado mais coerente aos distintos métodos, o que, inclusive, auxilia na definição do ponto de corte do dendrograma (CRUZ; REGAZZI; CARNEIRO, 2012). Deste modo, as relações entre os genótipos foram estudadas por meio das seguintes análises multivariadas: Otimização de Tocher, Componentes Principais e 
Dissimilaridade genética, expressa em dendrograma, com base no Método do Vizinho Mais Próximo. As estimativas foram calculadas utilizando as distâncias genéticas, calculadas a partir da Distância Euclidiana Média. Todas as análises estatísticas foram realizadas no programa GENES (CRUZ, 2001), seguindo modelos ilustrados por Cruz e Regazzi (1994).

\section{RESULTADOS E DISCUSSÃO}

Os genótipos avaliados apresentaram variação para as médias de massa dos frutos, cujos valores obtidos variaram entre 1,37 g para o genótipo PAR 3 e 2,51 g para o genótipo EM 4, com média de 1,81 g. Trabalhando com a espécie $B$. verbascifolia, em Minas Gerais, Gusmão, Vieira e Fonseca Júnior (2006) encontraram frutos com massa de matéria fresca entre 0,27 g e 2,34 g. Enquanto, Silvério e Fernandes-Bulhão (2009), no estado do Mato Grosso obtiveram valores médios de frutos variando de $0,17 \mathrm{~g}$ a 0,43 g para espécie $B$. crassa e massa média de frutos de 1,41 g a 3,97 g em B. orbignyana. Já Carvalho e Muller (2005) obtiveram valores de massa de frutos superiores de 3,2 g para a espécie $B$. crassifolia.

Os frutos dos genótipos de muricizeiros apresentaram diâmetros que variaram de 11,08 (EM 3) a 16,83 mm (EM 4). Em frutos da espécie B. verbascifolia, Gusmão, Vieira e Fonseca Júnior (2006) encontraram diâmetro variando entre 7,8 e 16,5 mm. Enquanto, Silvério e Fernandes-Bulhão (2009) obtiveram valores médios de diâmetros de 0,60 a $0,92 \mathrm{~mm}$ para $B$. crassa e médias de 12,40 a 19,50 mm para B. orbignyana.

Com relação ao comprimento dos frutos, houve variação para essa variável, com média de 10,23 mm para o genótipo PAC 0 e 14,70 mm para o genótipo PAC 6, com média geral de 11,74 mm. Enquanto, em frutos de murici da espécie $B$. verbascifolia a média de comprimento foi entre 7,3 e 13,9 mm (GUSMÃO; VIEIRA; FONSECA JÚNIOR, 2006). Já para a espécie B. crassa o comprimento variou de 0,59 a 1,10 mm. Para a espécie $B$. orbignyana, o comprimento médio obtido variou entre 11,40 a 19,7 mm (SILVÉRIO; FERNANDES-BULHÃO, 2009).

O genótipo de muricizeiro PAR 12 apresentou maior firmeza dos frutos, com média de 9,07 N, enquanto, o genótipo PAC 2 apresentou a menor média $1,83 \mathrm{~N}$, com média geral de 4,71 N. Vale ressaltar que não foram encontradas informações quanto à firmeza e cor de frutos de muricizeiros na literatura.

Os genótipos apresentaram médias de 71,51 para luminosidade (L), 5,84 para coordenada $a^{*}$ e 66,75 para coordenada $b^{*}$.
Quanto à percentagem de rendimento de polpa (epicarpo + mesocarpo) de murici, observa-se pouca variabilidade entre os genótipos. Pode-se verificar nesta característica variação de rendimento de polpa entre os muricizeiros estudados, com rendimento médio variando entre $79,87 \%$ para o genótipo PAC 1 e $84,54 \%$ para o genótipo, PAC 6 , com média geral de $82,27 \%$. Os genótipos de muricizeiros estudados apresentaram alto rendimento, cujo rendimento foi superior ao encontrado para a espécie $B$. verbascifolia por Gusmão, Vieira e Fonseca Júnior (2006), com rendimento de $73,63 \%$. Entretanto, tal resultado foi semelhante ao encontrada por Carvalho e Muller (2005) para a espécie B. crassifolia $83,3 \%$.

Quando comparado o rendimento de murici em relação a frutos com altos rendimentos de polpa, observou-se resultados superiores ou semelhantes aos frutos do gênero Spondia, como $S$. purpúrea, com rendimento de $67,77 \%$ (FILGUEIRAS et al., 2001a). Já para $S$. mombin, a porcentagem de polpa foi de $81,65 \%$ (FILGUEIRAS et al., 2001b). De acordo com Lima et al. (2002), este gênero apresenta rendimento de polpa superior a $50 \%$ demonstrando condições adequadas para comercialização. Carvalho, Nazaré, Oliveira (2003) em experimentos com frutos de bacuri, relatam que maior rendimento de polpa dos frutos, indica-os tanto para o consumo na forma de fruta fresca, quanto para utilização agroindustrial.

Os coeficientes de repetibilidade estimados variaram de muito baixos (L) a altos (rendimento), não havendo para a maioria das características avaliadas, exceto para firmeza, L e b* significativa ação do ambiente, o que pode ser confirmado pela superioridade dos valores de variâncias genéticas (entre genótipos) em relação às variâncias residuais (dentre genótipos). Independente das estimativas dos coeficientes de repetibilidade, os coeficientes de determinação variaram de 81,82 (L) a $99,12 \%$ (Comprimento), podendo ser classificados como altos. Provavelmente, os valores estimados para os coeficientes de determinação tenham sido altos devido ao número de medições adotadas, considerou-se 30 para cada característica avaliada, exceto para rendimento, com três repetições para $100 \mathrm{~g}$ de polpa. Observou-se que são necessárias mais medições, das variáveis estudadas, para um mesmo nível de certeza, quanto menor for o valor estimado do coeficiente de repetibilidade e vice-versa (Tabela 1).

Houve correlações positivas significativas (Tabela 2) entre a variável massa total do murici, para diâmetro de 0,80 mm e comprimento de 0,47 $\mathrm{mm}$ do fruto, logo, pode-se afirmar que ambas as variáveis influenciam a variável massa total. Todavia, pela magnitude da correlação e pelos níveis de significância estimados, o diâmetro influencia mais que o comprimento do fruto 
Tabela 1 - Estimativas da variância residual, variância genética, coeficiente de repetibilidade, coeficiente de determinação e do número de medições necessárias para obtenção dos níveis de certeza de 95 e 99\%, para as características físicas dos frutos de muricizeiros

\begin{tabular}{lcccccc}
\hline \multirow{2}{*}{ Caracteres } & Variância Residual & Variância Genética & Coeficiente de & Coeficiente de & \multicolumn{2}{c}{ Número* de medições para $\mathrm{R}^{2}$} \\
\cline { 2 - 7 } & (dentre plantas) & (entre plantas) & Repetibilidade & Determinação & 0,95 & 0,99 \\
\hline Massa & 0,065 & 0,128 & 0,67 & 98,38 & 9 & 49 \\
Diâmetro & 0,742 & 1,727 & 0,71 & 98,63 & 8 & 41 \\
Comprimento & 0,409 & 1,502 & 0,79 & 99,12 & 5 & 26 \\
Rendimento & 0,390 & 1,995 & 0,83 & 93,65 & 4 & 20 \\
Firmeza & 10,614 & 3,626 & 0,28 & 91,98 & 50 & 256 \\
L & 7,933 & 0,524 & 0,13 & 81,82 & 127 & 660 \\
a & 2,988 & 4,325 & 0,61 & 97,91 & 12 & 64 \\
b & 12,721 & 4,076 & 0,27 & 96,61 & 52 & 272 \\
\hline */ valores absolutos & & & & &
\end{tabular}

*/valores absolutos

Tabela 2 - Correlações fenotípicas entre as características físicas avaliadas

\begin{tabular}{lccccccc}
\hline Caracteres & $\mathrm{b}$ & $\mathrm{a}$ & $\mathrm{L}$ & Firmeza & Rendimento & Comprimento & Diâmetro \\
\hline Massa & $-0,04$ & $-0,29$ & 0,24 & $-0,29$ & 0,06 & $* 0,47$ & $* * 0,80$ \\
Diâmetro & $-0,14$ & $-0,42$ & 0,31 & $-0,08$ & 0,18 & $-0,09$ & \\
Comprimento & 0,13 & 0,30 & 0,01 & $-0,16$ & $-0,08$ & & \\
Rendimento & $-0,06$ & 0,12 & 0,14 & 0,32 & & & \\
Firmeza & $* *-0,64$ & 0,34 & $-0,15$ & & & & \\
L & $* 0,51$ & $-0,33$ & & & & & \\
a & $-0,08$ & & & & & & \\
\hline
\end{tabular}

*significativo a $5 \%$; **significativo a $1 \%$, pelo teste $\mathrm{T}$

na determinação da massa total dos frutos. A maioria dos genótipos de murici apresentou diâmetro maior que o comprimento, indicando predominância do formato oblongo, porém, a falta de correlação entre estas duas variáveis sugere variações no formato.

A relação da coordenada $b^{*}$ com a firmeza (Tabela 2) é negativa, onde frutos mais maduros apresentam menor firmeza e com L (Luminosidade) de forma positiva e possuem maior brilho. Segundo Chitarra e Chitarra (2005) os produtos de cor forte e brilhante são os preferidos, embora, a cor na maioria dos casos não contribua para maior valor nutritivo ou qualidade do produto.
A análise de agrupamento feito por meio da Otimização de Tocher, com base na Distância Euclidiana Média, permitiu a formação de quatro grupos, sendo que três grupos compreenderam apenas um genótipo, enquanto, os demais genótipos concentraram-se em apenas um grupo (Tabela 3). Segundo Cruz e Regazzi (1994), muitos grupos com apenas um genótipo permitem a formação de dezenas de populações segregantes, melhorando a possibilidade de obtenção de genótipos superiores em relação às características de interesse econômico.

A dispersão gráfica da análise de componentes principais (Figura 1), envolvendo os dois principais

Tabela 3 - Formação de grupos por meio da otimização de Tocher, com base na Distância Euclidiana Média

\begin{tabular}{lc}
\hline Grupo & Indivíduos \\
\hline 1 & PAR 3, PAR 12, PAR 11, EM 1, PAC 1, EM 5, PAR 5, PAC 0, PAC 2, PAR 7, PAC 3, PAC 7, PAR 4, PAR 9 e PAC 5 \\
2 & EM 3 \\
3 & PAC 6 \\
4 & EM 4 \\
\hline
\end{tabular}


Figura 1 - Dispersão gráfica (2D) da análise de componentes principais das características físicas dos frutos de muricizeiros, ilustrado pela formação de grupos da Tabela 3

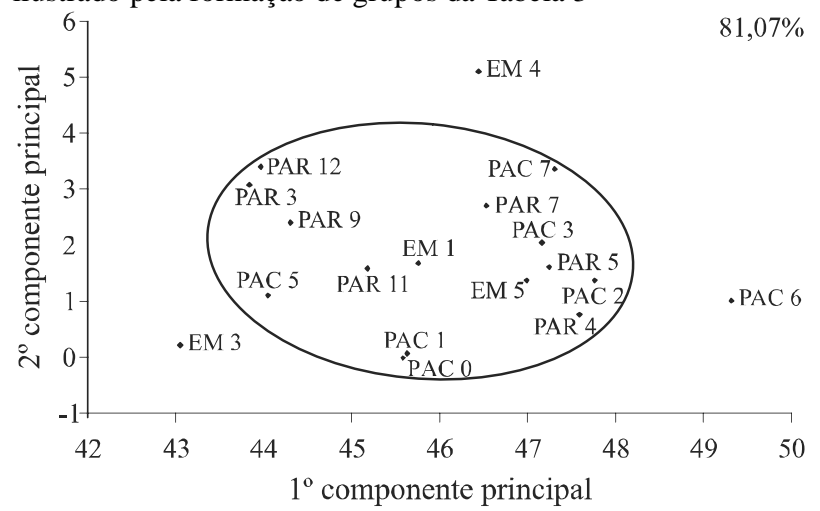

componentes, os quais responderam por $81,07 \%$ da variação total entre os genótipos, foi coerente com a formação de grupos (Tabela 2), confirmando o destaque dos genótipos EM 3, EM 4 e PAC 6 como distintos entre si e dos demais. Quando as duas primeiras variáveis canônicas explicam acima de $80 \%$ da variação total, sua utilização é satisfatória no estudo da divergência genética (CRUZ; REGAZZI, 1994).

Adicionalmente, o dendrograma de dissimilaridade dos genótipos (Figura 2), construído com base no Método do Vizinho mais Próximo, corroborou com os resultados alcançados, tanto pela otimização de Tocher quanto pela análise de componentes principais.

Figura 2 - Dissimilaridade dos genótipos por meio do método do Vizinho Mais Próximo envolvendo todas as características físicas avaliadas

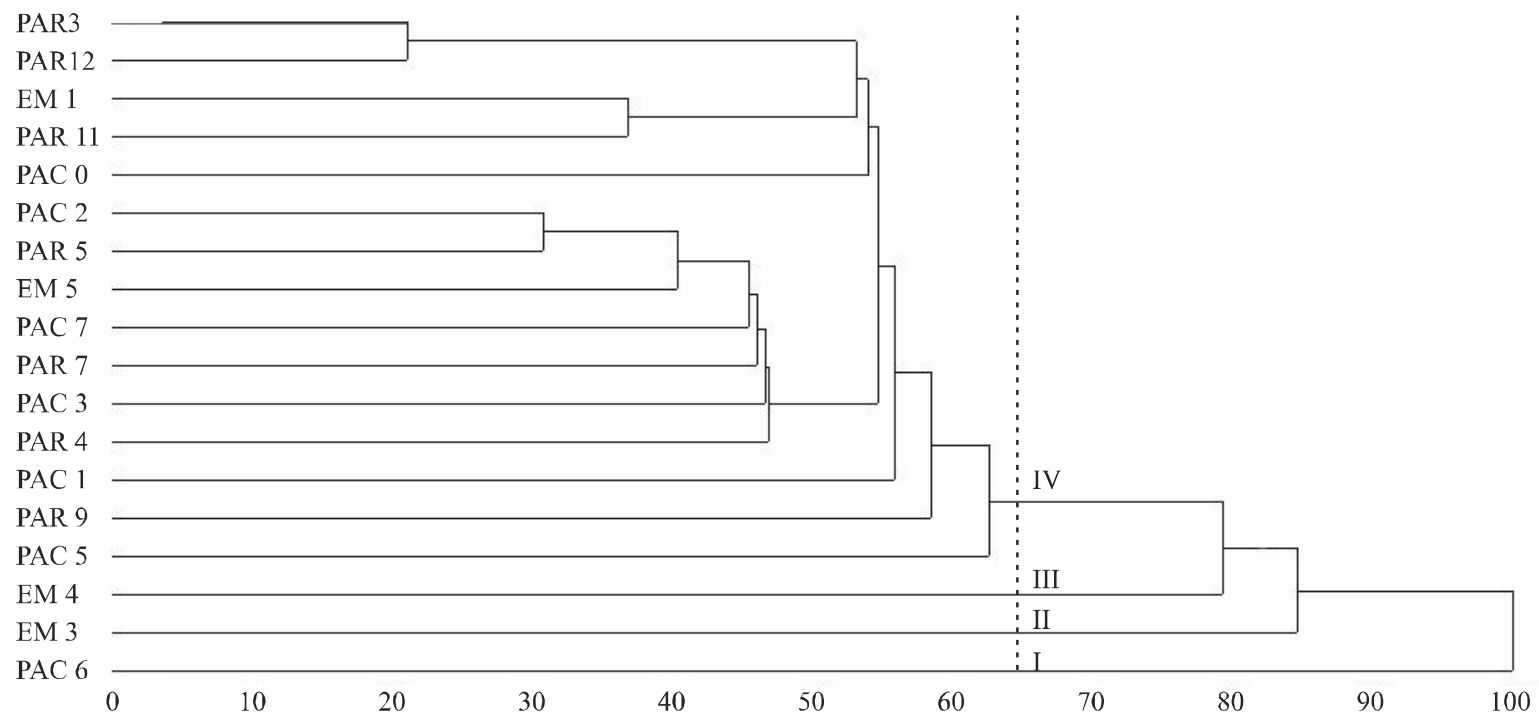

\section{CONCLUSÕES}

1. Os genótipos estudados, exceto EM 3 apresentaram diâmetro maior que o comprimento, caracterizando predominância a frutos oblongos;

2. O genótipo EM 4 apresentou maior massa dos frutos;

3. As características estudadas, exceto firmeza, L e b* não apresentaram significativa ação do ambiente;

4. Os genótipos EM 3, EM 4 e PAC 6 foram divergentes entre si e entre os demais genótipos, apresentando potencial para programas de melhoramento.

\section{AGRADECIMENTOS}

Os autores agradecem ao CNPq pelo suporte financeiro dado a esta pesquisa, à Capes pela bolsa de mestrado da primeira autora, à Embrapa Agroindústria Tropical pelo fornecimento de suas instalações e à Universidade Federal do Ceará pelo curso de Pósgraduação em Agronomia/Fitotecnia.

\section{REFERÊNCIAS}

ALVES, G. L.; FRANCO, M. R. B. Headspace gas chromatography-mass spectrometry of volatile compounds 
in murici (Byrsonima crassifolia L. Rich). Journal of Chromatography A, v. 985, n. 4, p. 297-301, 2003.

ASSUNÇÃO, S. L.; FELFILI, J. M. Fitossociologia de um fragmento de cerrado sensu stricto na APA do Paranoá, DF, Brasil. Acta Botanica Brasílica, v. 18, n. 4, p. 903-909, 2004.

CARVAlHO, J. E. U. de; NAZARÉ, R. F. R.; OLIVEIRA, W. M. Características físicas e físico-químicas de um tipo de bacuri (Platonia insignis Mart.) com rendimento industrial superior. Revista Brasileira de Fruticultura, v. 25, n. 2, p. 326-328, 2003.

CARVAlHo, J. E. U. de.; MÜLLER, C. H. Biometria e rendimento percentual de polpa de frutas nativas da Amazônia. Belém: Embrapa Amazônia Oriental, 2005. (Comunicado técnico, 139)

Chitarra, M. I. F.; CHITARRA, A. B. Pós-colheita de frutas e hortaliças: fisiologia e manuseio. 2. ed. Lavras: UFLA, 2005. $785 \mathrm{p}$.

COSTA, M. R.; OLIVEIRA, M. do S. P.; MOURA, E. F. Variabilidade genética em açaizeiro (Euterpe oleracea Mart.). Biotecnologia Ciência \& Desenvolvimento, n. 21, p. 46-50, 2001.

CRUZ, C. D. Programa Genes: aplicativo computacional em genética e estatística. Viçosa, Minas Gerais: UFV, 2001. 648 p.

CRUZ, C. D.; REGAZZI, A. J. Modelos biométricos aplicados ao melhoramento genético. Viçosa: UFV, 1994. 390 p.

CRUZ, C. D.; REGAZZI, A. J.; CARNEIRO, P. C. S. Modelos biométricos aplicados ao melhoramento genético. v. 1, 4. ed. Viçosa: UFV, 2012.514 p.

DONADIO, L. C.; MÔRO. F. V.; SERVIDONE, A. A. Frutas brasileiras. Jaboticabal, 2002. p. 222-224.

DUTRA FILHO, J. A. et al. Aplicação de técnicas multivariadas no estudo da divergência genética em cana-de-açúcar. Revista Ciência Agronômica, v. 42, n. 1, p. 185-192, 2011.

FERREIRA, A. et al. Repetibilidade e número de colheitas para seleção de clones de cana-de-açúcar. Pesquisa Agropecuária brasileira, v. 40, n. 8, p. 761-767, 2005.

FILGUEIRAS, H. A. C. et al. Calidad de frutas nativas de latinoamerica para industria: ciruela mexicana (Spondias purpurea L.). Proceedings-of-the-Interamerican-Society-forTropical-Horticulture, v. 43, p. 68-71, 2001a.

FILGUEIRAS, H. A. C. et al. Calidad de frutas nativas de latinoamerica para industria: jobo (Spondias mombin L.). Proceedings-of-the-Interamerican-Society-for-TropicalHorticulture, v. 43, p. 72-76, 2001 b.
GUSMÃO, E.; VIEIRA, F. de A.; FONSECA JÚNIOR, E. M. da. Biometria de frutos e endocarpos de murici (byrsonima verbascifolia rich. ex a. juss.). Cerne, v. 12, n. 1, p. 84-91, 2006.

LIMA, E. D. P. A. et al. Caracterização física e química dos frutos da umbu-cajazeira (Spondias spp) em cinco estádios de maturação da polpa congelada e néctar. Revista Brasileira de Fruticultura, v. 24, n. 2, p. 338-343, 2002.

NEGREIROS, J. R. da S. et al. Estimativas de repetibilidade de caracteres de produção em laranjeiras-doces no Acre. Pesquisa Agropecuária Brasileira, v. 43, n. 12, p. 1763-1768, 2008.

PEIXOTO, N. et al. Características agronômicas, produtividade, qualidade de vagens e divergência genética em feijão-vagem de crescimento indeterminado. Horticultura Brasileira, v. 20, n. 3, p. 447-451, 2002.

PEREIRA, J. O. P. O Papel de Abelhas do Gênero Centris na Polinização e Sucesso Reprodutivo do Muricizeiro (Byrsonima crassifolia, L.). 2001.59 f. Dissertação (Mestrado em Zootecnia) - Universidade Federal do Ceará, Fortaleza, 2001.

REZENDE, C. M.; FRAGA, S. R. Chemical and aroma determination of the pulp and seeds of murici (Byrsonima crassifolia L.). Journal Brazilian Chemistry Society, v. 14, n. 3, p. 425-428, 2003.

SANTOS, M. S. M. dos et al. Repetibilidade de características agroindustriais em cana-de-açúcar. Pesquisa Agropecuária Brasileira, v. 39, n. 4, p. 301-306, 2004.

SHIMOYA, A. et al. Repetibilidade de características forrageiras do capim-elefante. Scientia Agrícola, v. 59, n. 2, p. 227-234, 2002.

SILVÉRIO, D. V.; FERNANDES-BULHÃO, C. Fenologia reprodutiva e biometria de frutos e sementes de três espécies de Byrsonima Rich. ex Kunth (Malpighiaceae) no Parque do Bacaba, Nova Xavantina - Mato Grosso. Revista de Biologia Neotropical, v. 6, n. 1, p. 55-73, 2009.

SOARES, E. B. et al. Repetibilidade e correlações entre caracteres morfo-agronômicos de cajazeira. Ciência e agrotecnologia, v. 32, n. 6, p. 1851-1857, 2008.

TOQUICA, S. P. et al. Molecular characterization by AFLPs of Capsicum germplasm from the Amazon department in Colombia. Genetic Resources and Crop Evolution, v. 50, n. 6, p. 639-647, 2003.

ZEWDIE, Y.; TONG, N.; BOSLAND, P. Establishing a core collection of Capsicum using a cluster analysis with enlightened selection of accessions. Genetic Resources and Crop Evolution, v. 51, n. 2, p. 147-151, 2004. 